Université กำ
de Montréal

Serge Sultan, Université de Montréal

How to cite this article:

Dumont, É., Bourque, C. J., Duval, M., Payot, A., Sultan, S., \& Butterflies/Papillons Research Team. (2020). A Portrait of Self-Reported Health and Distress in Parents Whose Child Died of Cancer. OMEGA-Journal of Death and Dying, September 2020. DOI: https://doi.org/10.1177\%2F0030222820959943

DOI: $\quad$ https://doi.org/10.1177\%2F0030222820959943

PMID: $\quad 32954944$ 


\title{
A portrait of self-reported health and distress in parents whose child died of cancer
}

\author{
Émilie Dumont, M.Sc. ${ }^{1,2}$ \\ Claude Julie Bourque, Ph.D. ${ }^{2,3}$ \\ Michel Duval, M.D. ${ }^{2,3}$ \\ Antoine Payot, M.D., Ph.D. ${ }^{2,3}$ \\ Serge Sultan, Ph.D. ${ }^{1,2,3^{*}}$ \\ and the Butterflies/Papillons Research Team* \\ ${ }^{1}$ Department of Psychology, Université de Montréal, Montréal, Québec, Canada \\ ${ }^{2}$ Sainte-Justine University Health Center (SJUHC), Montréal, Québec, Canada \\ ${ }^{3}$ Department of Pediatrics, Université de Montréal, Montréal, Québec, Canada
}

\begin{abstract}
Author Note
*The Butterflies/Papillons Research Team is responsible for the bereaved parents followup study at Sainte-Justine UHC (Québec, Canada) and is composed of the following individuals, expert patients, clinicians and health services managers sharing equal responsibilities and authorship for the present paper: Carol Beaudry, Sylvie Cantin,
\end{abstract}


Geneviève Cardinal, Marie-Claude Charette, Lysane Daoust, Isabelle Desjardins, Nago Humbert, Marie-France Langlet, Audrey Stypulkowski.

We have no known conflict of interest to disclose.

Correspondence concerning this article should be addressed to Dr. Serge Sultan,

Sainte-Justine UHC

3175, Chemin de la Côte-Sainte-Catherine

Montréal H3T 1C5

Québec

Phone number: 514-343-6111 ext. 20727

Fax number: 514-343-2285

$\underline{\text { serge.sultan@umontreal.ca }}$

Keywords: bereaved parents, pediatric cancer, quality of life, psychological distress, grief symptoms 


\begin{abstract}
Grieving a child following cancer is a substantially difficult task. The objectives of this research were: 1) to describe current quality of life (QoL), psychological distress and symptoms of grief of bereaved parents, and 2) to explore the role of possible contributors of QoL and psychological distress. Forty-six parents (32 mothers) of children who died of cancer were surveyed on their QoL, distress, and complicated grief. Data were analyzed using multiple linear regression. Parents had a high frequency of grieving symptoms (58\%). Mothers reported more retrospective grief symptoms than fathers when describing the year after child death. Current lower mental well-being was associated with experiencing higher retrospective grief symptoms, a shorter period since child death, and being a father. Hence, parents experienced disturbances even long after child death. Mothers and fathers may present specificities that should be considered when developing supportive activities for this vulnerable population.
\end{abstract}

Keywords: bereaved parents, pediatric cancer, quality of life, psychological distress, grief symptoms 


\section{A portrait of self-reported health and distress in parents whose child died of cancer}

\section{Introduction}

Childhood cancer remains the most common cause of disease-related death in children. In Canada, there is an average of 119 deaths from cancer per year among children aged 0-14 years old and 290 deaths among 15-29 years old (Canadian Cancer Society, 2017).

Previous research has shown that grieving parents experience the most intense grief reactions when compared to grieving spouses or other situations (Middleton et al., 1998). Losing a child has been associated with higher risks of experiencing problematic or prolonged grief (Cacciatore et al., 2014) and more frequent or intense psychological symptoms such as depression or post-traumatic stress (Norberg et al., 2011). They are also more likely to experience marital disruption and relationship dissatisfaction than the general population (Hendrickson, 2009; Li et al., 2005).

Few reports have studied differences between mothers and fathers though, especially in the context of pediatric cancer. What we do know is that the intensity of mourning for mothers and fathers may not coincide, resulting in different needs (Endo et al., 2015). Authors have suggested that coping strategies may differ between mothers and fathers, with mothers using more emotional social sharing and fathers using avoidance and problem solving (Bergstraesser et al., 2015; Decinque et al., 2006). Qualitative studies on mother-father differences show that mothers experience more strongly shame, anxiety and sadness, and report more frequently intrusive thoughts, blame, adjustment problems and sleep disorders (Decinque et al., 2006; Duncan \& Cacciatore, 2015). 
The trajectory of parents' adjustment following child death is also poorly studied. Parents, 4-6 years after the death of their child, have shown higher risks of poor psychological well-being measured by the Center for Epidemiologic Studies Depression Scale (CES-D) and the Spielberger State-Trait Anxiety Inventory (STAI-Y), when compared to parents 7-9 years after the child's death (Kreicbergs et al., 2004). Similarly, a study has found a decrease in post-traumatic stress in fathers and mothers $(n=37)$ over the five years following the death (Ljungman et al., 2015).

However, we still do not know much on the long-term effects of grief on parents and their overall health. Little is known about how grief symptoms evolve over time. Finally, the population of fathers is clearly understudied with fathers being generally underrepresented in previous groups (Rosenberg et al., 2012). We designed this study to further document adjustment in bereaved parents and compare adjustment in mothers and fathers. We wished to document the evolution of grief symptoms in this group. The objectives of this study were 1) to describe quality of life, psychological distress, and grief symptoms in a new group of parents 2) to explore the role of contributors to current parents' physical and psychological health, including gender and time since child death.

\section{Methods}

The study was a one-site cross-sectional psychosocial survey. The project received approval from the Research Ethics Committee at Sainte-Justine UHC and all participants provided an informed consent (approval \# F9-17744). The present study was part of the Butterflies/Papillons project aiming at studying grief among parents of children who have died of cancer. It includes several aspects including psychosocial health and quality of life, the end-of-life context, use of palliative care, adjustment within 
parental couples, trajectory and adjustment activities, and attitudes toward bereavement research. In the present study, we focused on quantitative measures of QoL, psychological distress, and grief symptoms.

\section{Participants}

The inclusion criteria were: 1) death of children from pediatric cancer at the hematology-oncology department; 2) death from 2000 to 2016. Four exclusion criteria were applied before recruitment: 1) cases of families identified by our partner community organization (Leucan) as living acute distress or a crisis situation such as death of a parent, illness, depression, suicidal thoughts or attempt 2) cases identified by the hematology-oncology department staff as being in dispute at the time of the study, 3) families who were not able to read or write English or French.

At Sainte-Justine UHC, 226 children had died from cancer over the study period 2000-2016 (Figure 1). The study period was determined to maximize access to the list of cases and provide variability in time elapsed since death. Among the 226 deaths at the hematology-oncology department in the 2000-2016 period 211 cases of death, corresponding to a number more than 400 parents, were recognized as eligible for initial contact. A total of 15 cases were excluded post-hoc from the study because the cause of death was found as not attributable to cancer $(n=4)$, disputed deaths identified by the caregivers (e.g. possible medical error) $(n=6)$, as well as cases in distress, for which contact was not appropriate according to our partner community organization $(n=5)$. Among eligible families 211/226 (93.4\%), a large proportion of families who could not be reached had changed their contact details $(141 / 211,66.8 \%)$. We were able to leave a voice message to a total of 70 parents (29 fathers and 41 mothers). Of these, 8 parents 
declined the invitation and 16 parents did not follow up. Among the parents contacted $(n=70), 46$ parents $(46 / 70,66 \%)$ agreed to participate from 36 different families $(36 / 211$, 17\%). Hence, the final study sample was composed of 46 parents with 32 mothers and 14 fathers (including 1 stepfather) (Table 1). In the study sample, the average number of years elapsed since child death was $9.9 \pm 5.0$ years. Of these, 33 parents completed the long version of the questionnaire and 13 parents completed the short version (see measures).

\section{Figure 1}

Flow chart

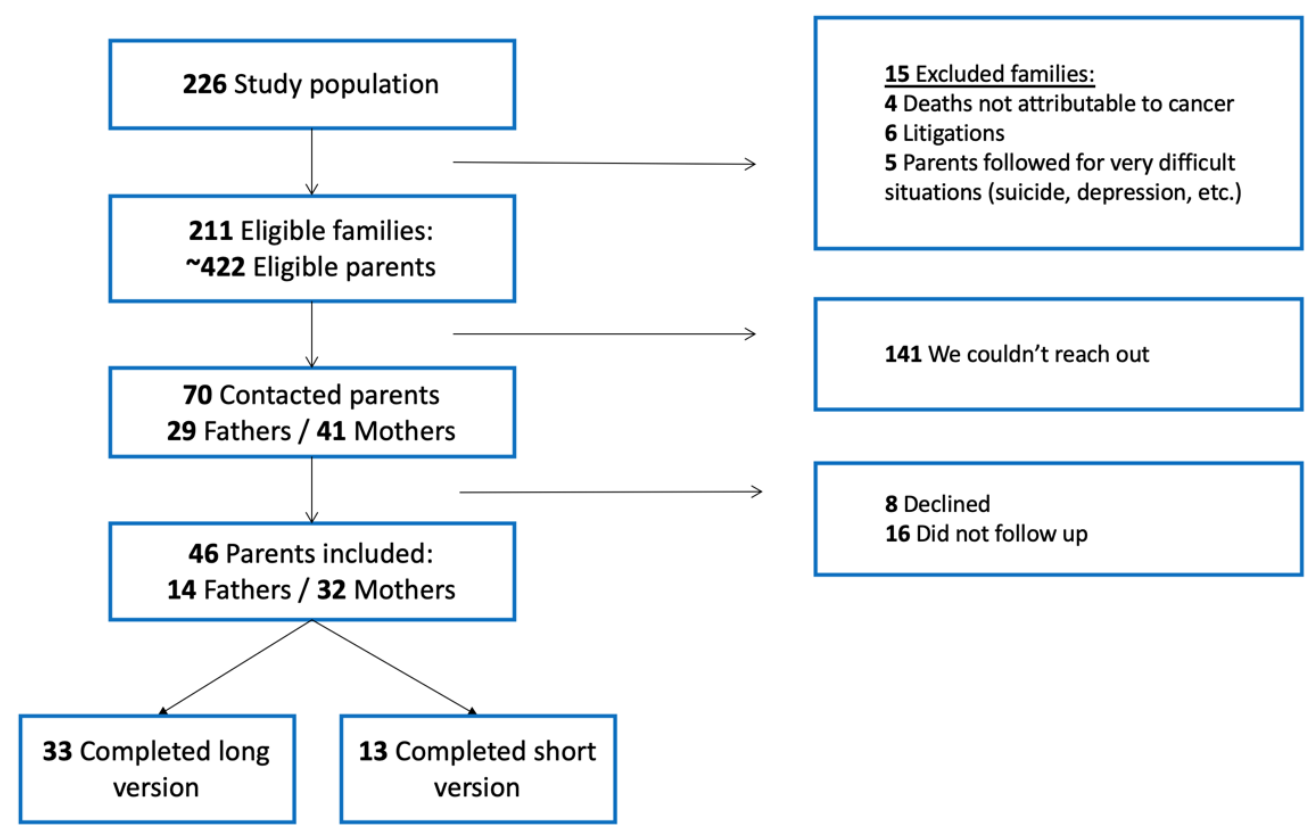

*Insert Table 1 here*

To avoid unnecessary burden in vulnerable parents, we included screening based on the last question from the Brief Symptom Inventory-18 "Thoughts of ending your 
life". Parents who scored 2 (moderately) to 4 (extremely) were directed to the short version of the questionnaire. These parents were not exposed to questions about their child's illness and death and were referred to the support team of our community partner (Labott et al., 2013).

A two-year limit (01/2016) was adopted to warrant a 24-month post-death before survey which is the most conservative restriction recommended in the literature (Albuquerque et al., 2016; Lichtenthal et al., 2015; Stevenson et al., 2017). We established a procedure for recruiting participants following recommendations on research with bereaved families (Clark, 2008; Stroebe \& Schut, 2010). We collaborated with caregivers from the cancer care centre and the palliative care unit, as well as members of a partner community organization (Leucan, https://www.leucan.qc.ca/en/). Caregivers initiated a first contact by telephone with eligible families from 09/2018 to 03/2019 in order to confirm contact information with potential participants and asked them about their interest. Then, the research team provided those who showed further interest with information about the project and followed up on their participation. The consent form was signed electronically when the parent entered the survey.

\section{Measures}

All measures were administered on an electronic platform (SurveyMonkey®). Responses regarding suicidal thoughts and all free comments were consulted within 24 hours of completion to determine if a psychosocial referral was required. Quality of Life and psychological distress measures were available in the full sample $(\mathrm{N}=46)$. Grieving symptoms (Now and Retrospect) were available only in those filling the longer form $(\mathrm{N}=33)$. 


\section{Quality of life}

We used the Medical Outcome Study Short Form-12 (MOS SF-12) (Gandek et al., 1998), a short (12 items) and widely used measure of QoL. Participants were asked to refer to the last three months to describe their perception on their physical and psychological well-being. A sample item is: "During the past week, how much of the time has your physical health or emotional problems interfered with your social activities (like visiting with friends, relatives, etc.)?" Following a standard coding algorithm using the 12 items, the tool provides two scores ranging 0-100, with 100 indicating the highest level of QoL and 50 indicating the population average. The two scores are Mental Component Summary (MCS) and Physical Component Summary (PCS). MCS reflects the dimensions of mental health, social functioning and psychological role limitations, while PCS reflects the dimensions of physical functioning, physical role limitations and physical pain (Gandek et al., 1998; Leplège, 2001; Misery et al., 2010; Ware \& Gandek, 1994; Ware Jr \& Sherbourne, 1992).

\section{Psychological distress}

We used the Brief Symptom Inventory (BSI-18) (Derogatis \& Savitz, 2000; Derogatis \& Spencer, 1993). The questionnaire consists of 18 items and three scales to measure anxiety (sample item: "Nervousness or shakiness inside"), depression (sample item: "Feeling hopeless about the future") and somatization (sample item: "Numbness or tingling in parts of your body") as well as a global scale, the Global Severity Index (GSI). Participants indicate how much each item have been an issue in the last 7 days from 0 (not at all) to 4 (extremely). The BSI-18 has been extensively used with parents in pediatric oncology (Zebrack et al., 2004; Zeltzer et al., 2009). In our sample, internal 
consistency $\alpha$ coefficients were .875 (anxiety), .949 (depression), .521 (somatization), and 0.933 on the global score. A participant was considered as a possible case when his/her overall scale score was above $\mathrm{T} \geq 63$ or two subscales were above 63 (Derogatis \& Spencer, 1993).

\section{Symptoms of grief}

We used the Inventory of Complicated Grief (ICG) (Prigerson et al., 1995). This questionnaire includes 19 items assessing indicators of complicated grief, such as anger, disbelief, and hallucinations. It includes sample item "I feel I cannot accept the death of the person who died". Each item is responded on a frequency scale from 0 (never) to 4 (always). A score above 25 has been suggestive of a high risk of psychological need and reflects the intensity of symptoms of grief (Keesee et al., 2008; Prigerson et al., 1995). The concurrent validity of the ICG was documented in previous research with strong associations with depression and measures of grief (Prigerson et al., 1995). For the

present study, we used this instrument twice with two separate time instructions. The first ("Now") invites the participant to complete the questionnaire by looking back to the last year, as is standard practice. The second ("Retrospect") requires participants to recall the first year following the child's death. In our sample, the internal consistency was $\alpha=.906$ and $\alpha=.907$ for the "Now" and "Retrospect" instructions respectively.

\section{Demographics and clinical data}

Participants provided the following data: participant age, relationship to the child, marital status, level of education, annual income and religion. We collected the following information from medical records: age of the child at death, year of death, and diagnosis.

\section{Data analysis}


For objective 1, we used descriptive statistics and comparisons with normative data, when available. For objective 2, we first used bivariate mean comparisons (Student t) and the associated effect size $(d)$. We compared the two versions of the ICG (Now/Retrospect) using a non-parametric Wilcoxon test due to the smaller sample. Then, we computed three multiple regression models to identify contributing factors to physical QoL (SF-12 PCS), mental QoL (SF-12 MCS), and psychological distress (BSI-18 GSI) in turn. Explanatory variables in these models were: parent's gender, parent's age at the time of death, child's age at the time of death, number of years since death, and symptoms of grief Now and Retrospect.

\section{Results}

\section{Descriptive analysis}

The average physical QoL level was close to normative standards, with mean PCS $=50.37, S D=7.49(d=.04, \mathrm{~ns})$. In contrast, the average mental QoL level was significantly lower than the normative 50, with $M C S=45.70, S D=10.33(d=0.42, p=$ .008). Mean levels of anxiety, depression, somatization, and distress were normative (Table 2 ). We found 8 positive cases of distress on the BSI-18 (6 mothers and 2 fathers, $18 \%$ in each group). Differences with norms were negligible (median $d=.12$, all ns). As for the symptoms of grief, we found 18/31 (58\%) parents showing a high intensity on their grieving (ICG-19>25) with this characteristic being somewhat more frequent in mothers $(14 / 20,70 \%)$ than in fathers $(4 / 11,36 \%)(p=.069)$. Symptoms of grief were higher compared to previous reports on other grieving population (Kersting et al., 2011; Newson et al., 2011).

*Insert Table 2 here* 


\section{Differences across gender and recall period}

We found no significant differences between mothers and fathers on QoL (SF-12), psychological distress (BSI-18) and current grief symptoms (ICG-19) (Table 2). In contrast, when asked to describe the 12-month period following death, mothers reported experiencing more frequently significant grief symptoms than fathers $(91 \%$ vs $55 \%, p=$ .016) Reported grief symptoms were particularly acute for mothers when referring to this period $(M=41.50, S D=13.21)$, when compared to fathers $(M=29.36, S D=12.71)(d=$ .97 , large effect size). Furthermore, we detected time differences in mothers only $(d=$ .98 , large) as compared to fathers $(d=.39$, medium) (Table 3$)$. Consistent with this observation, both time points Now and Retrospect ICG-19 measures were much more aligned in fathers $(r=.61)$ than in mothers $(r=.11)$.

*Insert Table 3 here*

\section{Contributing factors to parental health}

The data confirmed these observations in multivariate models (Table 4). When exploring contributors of current Physical QoL, the first regression model was not significant and was therefore rejected. Mental QoL $\left(\operatorname{adj} . R^{2}=35.3 \%, p=.011\right)$ and psychological distress $\left(a d j . R^{2}=39.4 \%, p=.006\right)$ models were significant with common contributing factors. A higher current mental QoL was associated with a longer period since child death $(\beta=.344, p=.038)$ and lower retrospective symptoms of grief $(\beta=-$ $.494, p=.019)$. Consistently, higher levels of current psychological distress were associated with a shorter period since child death $(\beta=-.340, p=.034)$ and more intense 
retrospective symptoms of grief $(\beta=.474, p=.019)$. Notably, psychological distress was also associated with being a father $(\beta=.385, p=.031)$. Parent's age at the time of death, the child's age at the time of death, and current symptoms of grief did not contribute to mental QoL or psychological distress.

\section{*Insert Table 4 here*}

\section{Discussion}

Despite extensive research on bereavement, there are still few studies on the longterm adjustment of parents who lost their child to cancer. We surveyed a group of 46 parents on average 10 years after child death and found lower mental QoL than norms, as well as lower mental well-being to be associated with a shorter period since death, more acute retrospective symptoms of grief, and being a father.

This global picture further documents the common observation that bereaved parents remain a vulnerable population long after their child death. This was particularly clear in the present sample from the low mental quality of life and frequent significant symptoms of grief. Significantly high grief levels were present in more than half of the sample, more than twice the frequency found earlier in comparison sample with the same anteriority of death (58\% vs 24\%) (Kersting et al., 2011). High levels of grieving symptoms are reflected by experiences as feeling of emptiness without the child, the difficulty of accepting the death, experiencing anger, and the likes. Notably, when exploring differences between mothers and fathers in bivariate comparisons, we found very little difference. The only clear difference identified was on retrospective symptoms of grief being particularly higher in mothers than in fathers. In mothers, we found an 
original pattern suggestive of an adjustment process where time would be associated with a relative alleviation of symptoms of grief, whereas the pattern was less clear in fathers, in contrast with stability observed across time in other studies (Fujisawa et al., 2010). Observed levels of mental QoL and psychological distress in our sample are in line with previous observations suggesting there is little difference between mothers and fathers in the long-term (Song et al., 2010).

Normative levels of physical QoL and psychological distress found here suggest that time would help parents recover when grieving the loss of a child, consistent with previous studies showing a decreased of symptoms with time (Kreicbergs et al., 2004; Song et al., 2010). However, in our sample approximately 1 in 5 parents (18.6\%) still showed clinical risks of psychological distress long after the death. Psychological distress in fathers and mothers could be explained by unresolved grief. In fact, a national study conducted in Sweden suggests that $26 \%$ of parents had not worked through their grief up to 9 years after their child's death (Lannen et al., 2008). Two studies have also identified bereaved parents as having the highest frequency of significant grief symptoms (approximately 25\%), compared to other bereaved groups and the general population (35\%) (Kersting et al., 2011; Newson et al., 2011). In line with this result, we found that grief symptoms remained at a high level for many parents, and particularly mothers, for many years following the death of their child. The high frequency found in our sample suggests that the death of a child from cancer could be a major contributor of complicated grief (Kersting et al., 2011), perhaps because disturbing feeling of hopes and failures in relation to the cancer trajectory. Interestingly, contrasting with normative levels of distress, the high levels of grief observed here suggest that the experience of grieving is 
probably not well captured by traditional psychological symptoms and categories such as "depression", "anxiety", or "somatization" from the BSI-18.

Finally, when studying the unique contribution of factors to explain the current portrait of bereaved parents' health, we found that higher mental well-being was associated with a longer period since child death, and more acute grief reactions after child death (retrospective measure). This was in line with our previous bivariate analysis and is suggestive of a long-term adjustment process, and a contribution of grief symptoms to mental well-being independent of the other factors, and is consistent with the existing literature (Lannen et al., 2008; Wing et al., 2001). It also speaks of the acuteness of stress as a vulnerability factor for further adjustment processes. It is also possible that higher level of grief symptoms in the past may be contributing to unresolved grief and higher levels of psychological distress over time. These results are consistent with studies suggesting associations between unresolved grief and such concepts as depression or anxiety (Lannen et al., 2008).

Interestingly, when controlling for other factors in the present study, being a father appeared associated with poorer psychological distress. Several possible explanations might account for this phenomenon. Fathers show specificities on their coping strategies (Wijngaards-de Meij et al., 2008), being more oriented on restoration, using distraction from grief, denial, life changes, etc., while mothers tending to use more social support resources. Another hypothesis lies in traditional gender roles that hinder emotion expression and the recognition of one's weaknesses in fathers. Fathers have often reported how they are expected to be strong and be the pillar of the family (Cleiren, 2019; Dyregrov \& Matthiesen, 1987; Wing et al., 2001). In the present study they showed 
very high consistency over time in reported symptoms of grief. This could reflect that their current feelings remain as they were, indicating that the loss is incommensurable. The experience of mothers speaks for a different reality, one of evolution and adjustment, despite enduring intense signs of grief.

We should recognize the limitations of our study. First, the sample size limited the power of our analysis strategy. Second, the study is cross-sectional and causal interpretation should be made cautiously, especially as for the retrospective measure of symptoms of grief. We cannot rule out the impact of current mood on retrospective ratings in the multivariate analyses. Third, we should recognize a probable selection bias as we could not reach the most vulnerable parents or those having difficulty with the electronic platform. These limitations point to future needs in this field of research. Future studies should focus on prospective longitudinal research to better understand how the recovery process unfolds both for fathers and mothers.

In conclusion, in an electronic survey of 46 bereaved parents who lost a child to cancer for an average period of 10 years, we found low levels of mental QoL and high levels of grief symptoms. The results suggested that current lower psychological wellbeing of parents was related with a more recent death, more acute grief symptoms after death, and being a father. These observations support a slow process of adjustment in both parents, independent of the age of parents and the child, and some specificities across genders. Future research should address interrelationships between grieving symptoms and psychological distress, and explore longitudinally coping and adjustment both in mothers and fathers. Specificities to the clinical context of cancer should also be explored as it is unclear how they impact these processes. 


\section{Conflict of interests}

No conflict of interest to declare.

\section{Funding}

This work was supported by the Sainte-Justine UHC Foundation through an endowment to the Centre of Psycho-Oncology 


\section{References}

Albuquerque, S., Pereira, M., \& Narciso, I. (2016). Couple's relationship after the death of a child: a systematic review. Journal of Child and Family Studies, 25(1), 3053. https://doi.org/10.1007/s10826-015-0219-2

Bergstraesser, E., Inglin, S., Hornung, R., \& Landolt, M. A. (2015). Dyadic coping of parents after the death of a child. Death Studies, 39(3), 128-138. https://doi.org/10.1080/07481187.2014.920434

Cacciatore, J., Lacasse, J. R., Lietz, C. A., \& McPherson, J. (2014). A parent's tears: primary results from the traumatic experiences and resiliency study. OMEGAJournal of Death and Dying, 68(3), 183-205. https://doi.org/10.2190/OM.68.3.a

Canadian Cancer Society. (2017). Canadian cancer statistics 2017. In C. C. Society (Ed.), Chapter 2 : Mortality: How many people die of cancer in Canada by sex, age and geography? (Vol. 2018, pp. 46-59). Toronto, ON: Canadian Cancer Society.

Clark, T. (2008). 'We're over-researched here!' exploring accounts of research fatigue within qualitative research engagements. Sociology, 42(5), 953-970. https://doi.org/10.1177/0038038508094573

Cleiren, M. (2019). Bereavement and adaptation: a comparative study of the aftermath of death. New York: Taylor \& Francis.

Decinque, N., Monterosso, L., Dadd, G., Sidhu, R., Macpherson, R., \& Aoun, S. (2006). Bereavement support for families following the death of a child from cancer: experience of bereaved parents. Journal of psychosocial oncology, 24(2), 65-83. https://doi.org/10.1300/J077v24n02_05 
Derogatis, L. R., \& Savitz, K. L. (2000). The SCL-90-R and brief symptom inventory (BSI) in primary care. In M. E. Maruish (Ed.), Handbook of psychological assessment in primary care settings (p. 297-334). Lawrence Erlbaum Associates Publishers. https://doi.org/10.1037/t00789-000

Derogatis, L. R., \& Spencer, P. (1993). Brief symptom inventory: BSI: Pearson Upper Saddle River, NJ.

Duncan, C., \& Cacciatore, J. (2015). A systematic review of the peer-reviewed literature on self-blame, guilt, and shame. OMEGA-Journal of Death and Dying, 71(4), 312-342. https://doi.org/10.1177/0030222815572604

Dyregrov, A., \& Matthiesen, S. B. (1987). Similarities and differences in mothers' and fathers' grief following the death of an infant. Scandinavian Journal of Psychology, 28(1), 1-15. https://doi.org/10.1111/j.1467-9450.1987.tb00900.x

Endo, K., Yonemoto, N., \& Yamada, M. (2015). Interventions for bereaved parents following a child's death: a systematic review. Palliative Medicine, 29(7), 590604. https://doi.org/10.1177/0269216315576674

Fujisawa, D., Miyashita, M., Nakajima, S., Ito, M., Kato, M., \& Kim, Y. (2010). Prevalence and determinants of complicated grief in general population. Journal of affective disorders, 127(1-3), 352-358. https://doi.org/10.1016/j.jad.2010.06.008

Gandek, B., Ware, J. E., Aaronson, N. K., Apolone, G., Bjorner, J. B., Brazier, J. E., .. . Prieto, L. (1998). Cross-validation of item selection and scoring for the SF-12 Health Survey in nine countries: results from the IQOLA Project. Journal of 
clinical epidemiology, 51(11), 1171-1178. https://doi.org/10.1016/S0895-

\section{6(98)00109-7}

Hendrickson, K. C. (2009). Morbidity, mortality, and parental grief: a review of the literature on the relationship between the death of a child and the subsequent health of parents. Palliative \& Supportive Care, 7(1), 109-

119. https://doi.org/10.1017/S1478951509000133

Keesee, N. J., Currier, J. M., \& Neimeyer, R. A. (2008). Predictors of grief following the death of one's child: the contribution of finding meaning. Journal of clinical psychology, 64(10), 1145-1163. https://doi.org/10.1002/jclp.20502

Kersting, A., Brähler, E., Glaesmer, H., \& Wagner, B. (2011). Prevalence of complicated grief in a representative population-based sample. Journal of affective disorders, 131(1-3), 339-343. https://doi.org/10.1016/j.jad.2010.11.032

Kreicbergs, U., Valdimarsdóttir, U., Onelöv, E., Henter, J.-I., \& Steineck, G. (2004). Anxiety and depression in parents 4-9 years after the loss of a child owing to a malignancy: a population-based follow-up. Psychological Medicine, 34(8), 1431-1441. https://doi.org/10.1017/S0033291704002740

Labott, S. M., Johnson, T. P., Fendrich, M., \& Feeny, N. C. (2013). Emotional risks to respondents in survey research: some empirical evidence. Journal of Empirical Research on Human Research Ethics, 8(4), 53-66. https://doi.org/10.1525/jer.2013.8.4.53

Lannen, P. K., Wolfe, J., Prigerson, H. G., Onelov, E., \& Kreicbergs, U. C. (2008). Unresolved grief in a national sample of bereaved parents: impaired mental and 
physical health 4 to 9 years later. Journal of Clinical Oncology, 26(36), 5870. https://doi.org/10.1200/JCO.2007.14.6738

Leplège, A. (2001). Le questionnaire MOS SF-36: Manuel de l'utilisateur et guide d'interprétation des scores: De Boeck Secundair.

Li, J., Laursen, T. M., Precht, D. H., Olsen, J., \& Mortensen, P. B. (2005).

Hospitalization for mental illness among parents after the death of a child. New England Journal of Medicine, 352(12), 1190-1196.

https://doi.org/10.1056/NEJMoa033160

Lichtenthal, W. G., Sweeney, C. R., Roberts, K. E., Corner, G. W., Donovan, L. A., Prigerson, H. G., \& Wiener, L. (2015). Bereavement follow-up after the death of a child as a standard of care in pediatric oncology. Pediatric Blood \& Cancer, 62(S5). https://doi.org/10.1002/pbc.25700

Ljungman, L., Hovén, E., Ljungman, G., Cernvall, M., \& Essen, L. (2015). Does time heal all wounds? A longitudinal study of the development of posttraumatic stress symptoms in parents of survivors of childhood cancer and bereaved parents. Psycho-Oncology, 24(12), 1792-1798. https://doi.org/10.1002/pon.3856

Middleton, W., Raphael, B., Burnett, P., \& Martinek, N. (1998). A longitudinal study comparing bereavement phenomena in recently bereaved spouses, adult children and parents. Australian and New Zealand Journal of Psychiatry, 32(2), 235-241. https://doi.org/10.3109/00048679809062734 
Misery, L., Schmitt, A.-M., Boussetta, S., Rahhali, N., \& Taieb, C. (2010). Melasma: measure of the impact on quality of life using the French version of MELASQOL after cross-cultural adaptation. Acta dermato-venereologica, 90(3), 331-332. https://doi.org/ 10.2340/00015555-0837

Newson, R. S., Boelen, P. A., Hek, K., Hofman, A., \& Tiemeier, H. (2011). The prevalence and characteristics of complicated grief in older adults. Journal of affective disorders, 132(1-2), 231-238. https://doi.org/10.1016/i.jad.2011.02.021

Norberg, A. L., Pöder, U., \& von Essen, L. (2011). Early avoidance of disease-and treatment-related distress predicts post-traumatic stress in parents of children with cancer. European Journal of Oncology Nursing, 15(1), 80-84. https://doi.org/10.1016/j.ejon.2010.05.009

Prigerson, H. G., Maciejewski, P. K., Reynolds, C. F., Bierhals, A. J., Newsom, J. T., Fasiczka, A., . . Miller, M. (1995). Inventory of complicated grief: a scale to measure maladaptive symptoms of loss. Psychiatry research, 59(1), 65-79. https://doi.org/10.1016/0165-1781(95)02757-2

Rosenberg, A. R., Baker, K. S., Syrjala, K., \& Wolfe, J. (2012). Systematic review of psychosocial morbidities among bereaved parents of children with cancer. Pediatric blood \& cancer, 58(4), 503-512. https://doi.org/10.1002/pbc.23386

Song, J., Floyd, F. J., Seltzer, M. M., Greenberg, J. S., \& Hong, J. (2010). Long-term effects of child death on parents' health-related quality of life: a dyadic analysis. Family relations, 59(3), 269-282. https://doi.org/10.1111/j.1741$\underline{3729.2010 .00601 . x}$ 
Stevenson, M., Achille, M., Liben, S., Proulx, M.-C., Humbert, N., Petti, A., . . Cohen, S. R. (2017). Understanding how bereaved parents cope with their grief to inform the services provided to them. Qualitative health research, 27(5), 649664. https://doi.org/10.1177/1049732315622189

Stroebe, M., \& Schut, H. (2010). The dual process model of coping with bereavement: a decade on. OMEGA-Journal of Death and Dying, 61(4), 273-289. https://doi.org/10.2190/OM.61.4.b

Ware, J., John E, \& Gandek, B. (1994). The SF-36 health survey: development and use in mental health research and the IQOLA Project. International Journal of Mental Health, 23(2), 49-73. https://doi.org/10.1080/00207411.1994.11449283

Ware Jr, J. E., \& Sherbourne, C. D. (1992). The MOS 36-item short-form health survey (SF-36): I. Conceptual framework and item selection. Medical care, 473-483.

Wijngaards-de Meij, L., Stroebe, M., Schut, H., Stroebe, W., Bout, J., Heijden, P. G., \& Dijkstra, I. (2008). Parents grieving the loss of their child: interdependence in coping. British Journal of Clinical Psychology, 47(1), 31-42. https://doi.org/10.1348/014466507X216152

Wing, D. G., Burge-Callaway, K., Rose Clance, P., \& Armistead, L. (2001). Understanding gender differences in bereavement following the death of an infant: Implications of or treatment. Psychotherapy: Theory, Research, Practice, Training, 38(1), 60. https://doi.org/10.1037/0033-3204.38.1.60 
Zebrack, B. J., Gurney, J. G., Oeffinger, K., Whitton, J., Packer, R. J., Mertens, A., . . . Robison, L. L. (2004). Psychological outcomes in long-term survivors of childhood brain cancer: a report from the childhood cancer survivor study. Journal of Clinical Oncology, 22(6), 999-1006. https://doi.org/10.1200/JCO.2004.06.148

Zeltzer, L. K., Recklitis, C., Buchbinder, D., Zebrack, B., Casillas, J., Tsao, J. C., . . . Krull, K. (2009). Psychological status in childhood cancer survivors: a report from the childhood cancer survivor study. Journal of Clinical Oncology, 27(14), 2396. https://doi.org/10.1200/JCO.2008.21.1433. 
Table 1

Parents $(N=46)$ and child $(N=36)$ sociodemographic characteristics

\begin{tabular}{|c|c|}
\hline \multirow{3}{*}{$\begin{array}{l}\text { Parents' characteristics } \\
\text { Age }\end{array}$} & Parents $(\mathrm{N}=46)$ \\
\hline & M: 52.0 \\
\hline & SD: 9.8 \\
\hline & $N(\%)$ \\
\hline \multicolumn{2}{|l|}{ Relationship to the child } \\
\hline Father & $13(28.3)$ \\
\hline Mother & $32(69.6)$ \\
\hline Other $^{\mathrm{a}}$ & $1(2.2)$ \\
\hline \multicolumn{2}{|l|}{ Marital status } \\
\hline Single & $2(4.3)$ \\
\hline Married/Common-law partner & $38(82.6)$ \\
\hline Separated/divorced & $5(10.9)$ \\
\hline Widow(er) & $1(2.2)$ \\
\hline \multicolumn{2}{|l|}{ Level of education } \\
\hline No diploma & $5(10.9)$ \\
\hline Primary school degree & $1(2.2)$ \\
\hline High school degree & $10(21.7)$ \\
\hline Pre-university / technical college degree & $7(15.2)$ \\
\hline University degree & $22(47.8)$ \\
\hline Unsure of equivalence & $1(2.2)$ \\
\hline \multicolumn{2}{|l|}{ Annual income } \\
\hline$\leq 20,000 \$$ & $3(6.5)$ \\
\hline $20,000-60,000 \$$ & $7(15.2)$ \\
\hline$\geq 60,000 \$$ & $28(60.9)$ \\
\hline No indication & $8(17.4)$ \\
\hline Children's characteristics & Children (N=36) \\
\hline \multirow[t]{3}{*}{ Age } & M: 11.4 \\
\hline & SD: 6.5 \\
\hline & $N(\%)$ \\
\hline \multicolumn{2}{|l|}{ Year of death } \\
\hline $2013-2016$ & $9(25.0)$ \\
\hline $2009-2012$ & $6(16.7)$ \\
\hline $2005-2008$ & $13(36.1)$ \\
\hline 2000-2004 & $8(22.2)$ \\
\hline \multicolumn{2}{|l|}{ Gender } \\
\hline Male & $18(50.0)$ \\
\hline Female & $18(50.0)$ \\
\hline \multicolumn{2}{|l|}{ Diagnosis } \\
\hline Central nervous system tumour & $11(30.6)$ \\
\hline Bone tumour / osteosarcoma & $7(19.4)$ \\
\hline Malignant hemopathy & $9(25.0)$ \\
\hline Rhabdomyosarcoma & $4(11.1)$ \\
\hline Neuroblastoma & $2(5.6)$ \\
\hline Wilms' tumor & $2(5.6)$ \\
\hline Undifferentiated sarcoma & $1(2.8)$ \\
\hline
\end{tabular}




\section{Table 2}

Quality of life, psychological distress, and complicated grief in 46 fathers and mothers of deceased children

\begin{tabular}{|c|c|c|c|c|c|c|c|}
\hline & Total $(\mathrm{N}=45) \dagger$ & Fathers $(\mathrm{N}=13)$ & Mothers $(\mathrm{N}=32)$ & Cohen's d & Student T & & \\
\hline & $M(S D) / N(\%)$ & $M(S D) / N(\%)$ & $M(S D) / N(\%)$ & $d$ & $t$ & $d f$ & $p$ value \\
\hline \multicolumn{8}{|l|}{ Quality of Life } \\
\hline \multicolumn{8}{|l|}{ (MOS SF-12) } \\
\hline Physical (PCS-12) & $50.37(7.49)$ & $53.08(5.16)$ & $49.27(8.06)$ & $0.563^{\mathrm{aa}}$ & -1.573 & 43 & 0.123 \\
\hline \multirow[t]{3}{*}{ Mental (MCS-12) } & $45.70(10.33)$ & $48.81(8.84)$ & $44.43(10,75)$ & $0.445^{\mathrm{aa}}$ & -1.298 & 43 & 0.201 \\
\hline & Total $(\mathrm{N}=43) \dagger \dagger$ & Fathers $(\mathrm{N}=11)$ & Mothers $(\mathrm{N}=32)$ & Cohen's d & Student T & & \\
\hline & $M(S D) / N(\%)$ & $M(S D) / N(\%)$ & $M(S D) / N(\%)$ & Cohen's d & $t$ & $d f$ & $p$ value \\
\hline \multirow{2}{*}{\multicolumn{8}{|c|}{$\begin{array}{l}\text { Psychological distress } \\
\text { (BSI-18) }\end{array}$}} \\
\hline & & & & & & & \\
\hline Total GSI & $51.26(10.92)$ & $50.45(9.35)$ & $51.53(11.54)$ & $0.103^{\mathrm{a}}$ & 0.279 & 41 & 0.782 \\
\hline Positive cases & $8(18.60)$ & $2(18.18)$ & $6(18.75)$ & & & & \\
\hline Negative cases & $35(81.40)$ & $9(81,81)$ & $26(81.25)$ & & & & \\
\hline Anxiety & $49.69(10.22)$ & $45.55(9.25)$ & $51.13(10.28)$ & $0.571^{\mathrm{aa}}$ & 1.591 & 41 & 0.119 \\
\hline Depression & $53.40(11.86)$ & $53.46(11.4)$ & $53.38(12.19)$ & $0.009^{\mathrm{a}}$ & -0.019 & 41 & 0.985 \\
\hline \multirow[t]{3}{*}{ Somatization } & $51.07(7.65)$ & $50.18(7.24)$ & $51.38(7.88)$ & $0.159^{\mathrm{a}}$ & 0.442 & 41 & 0.661 \\
\hline & Total $(\mathbf{N}=33)$ & Fathers $(\mathrm{N}=11)$ & Mothers $(\mathrm{N}=22)$ & Cohen's d & Student T & & \\
\hline & $M(S D) / N(\%)$ & $M(S D) / N(\%)$ & $M(S D) / N(\%)$ & $d$ & $t$ & $d f$ & $p$ value \\
\hline \multicolumn{8}{|l|}{$\begin{array}{l}\text { Complicated Grief } \\
\text { (ICG-19) }\end{array}$} \\
\hline Retrospect & $37.52(13.76)$ & $29.36(12.71)$ & $41.59(12.62)$ & $0.966^{\text {aaa }}$ & $2.618 * *$ & 31 & 0.014 \\
\hline$>25$ & $26(78.79)$ & $6(54.54)$ & $20(90.91)$ & & & & \\
\hline$\leq 25$ & $7(21.21)$ & $5(45.45)$ & $2(9,09)$ & & & & \\
\hline Now & $26.71(13.65)$ & $24.46(12.41)$ & $27.95(14.45)$ & $0.259^{\mathrm{a}}$ & 0.676 & 29 & 0.504 \\
\hline$>25$ & $18(58.10)$ & $4(36.30)$ & $14(70,00)$ & & & & \\
\hline$\leq 25$ & $13(41.90)$ & $7(63.64)$ & $6(30,00)$ & & & & \\
\hline
\end{tabular}


Table 3

Grief symptoms scores on the ICG-19 across time

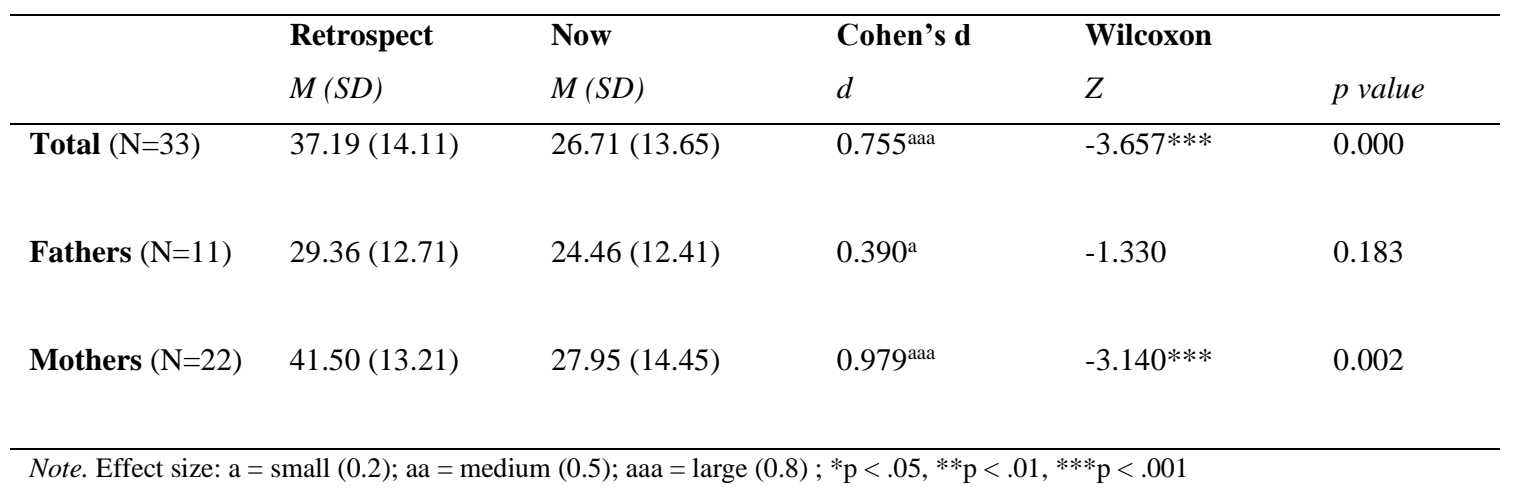




\section{Table 4}

Summary of Multiple Regressions Predicting for Quality of Life and Distress with Sociodemographic Characteristics and Complicated Grief

\begin{tabular}{|c|c|c|c|c|c|c|c|}
\hline $\begin{array}{l}\text { Models } \\
\text { Variables }\end{array}$ & $R^{2}$ & $\operatorname{adj.} R^{2}$ & $B$ & $S E$ & $\beta$ & $t$ & $\begin{array}{c}p \\
\text { value }\end{array}$ \\
\hline QoL - Physical (SF-12 PCS) & 0.300 & 0.117 & & & & & \\
\hline Gender : Father & & & 5.535 & 3.010 & 0.372 & 1.839 & 0.079 \\
\hline Age of child at the time of death & & & 0.661 & 0.301 & $0.572 *$ & 2.195 & 0.039 \\
\hline Age of parent at the time of death & & & -0.656 & 0.242 & $-0.721 *$ & -2.706 & 0.013 \\
\hline Number of years since death & & & 0.100 & 0.260 & 0.071 & 0.387 & 0.703 \\
\hline ICG Retrospect & & & 0.104 & 0.117 & 0.203 & 0.889 & 0.383 \\
\hline ICG Now & & & -0.027 & 0.105 & -0.052 & -0.259 & 0.798 \\
\hline QoL - Mental (SF-12 MCS) & $0.487 *$ & $0.353^{*}$ & & & & & \\
\hline Gender : Father & & & -5.553 & 2.721 & -0.354 & -2.041 & 0.053 \\
\hline Age of child at the time of death & & & 0.426 & 0.272 & 0.349 & 1,562 & 0.132 \\
\hline Age of parent at the time of death & & & -0.020 & 0.219 & -0.021 & -0.093 & 0.927 \\
\hline Number of years since death & & & 0.515 & 0.235 & $0.344^{*}$ & 2.197 & 0.038 \\
\hline ICG Retrospect & & & -0.269 & 0.106 & $-0.494 *$ & -2.529 & 0.019 \\
\hline ICG Now & & & -0.113 & 0.095 & -0.204 & -1.193 & 0.245 \\
\hline Psychological distress (GSI) & $0.519 * *$ & $0.394 * *$ & & & & & \\
\hline Gender : Father & & & 7.229 & 3.152 & $0.385^{*}$ & 2.293 & 0.031 \\
\hline Age of child at the time of death & & & -0.399 & 0.316 & -0.273 & -1.264 & 0.219 \\
\hline Age of parent at the time of death & & & 0.280 & 0.254 & 0.243 & 1.102 & 0.282 \\
\hline Number of years since death & & & -0.611 & 0.272 & $-0.340 *$ & -2.248 & 0.034 \\
\hline ICG Retrospect & & & 0.309 & 0.123 & $0.474 *$ & 2.511 & 0.019 \\
\hline ICG Now & & & 0.191 & 0.110 & 0.287 & 1.733 & 0.096 \\
\hline
\end{tabular}

